Part of Journal of Research of the National Bureau of Standards, Volume 21, July 1938

\title{
DETERMINATION OF ARSENIC, ANTIMONY, AND TIN IN LEAD-, TIN-, AND COPPER-BASE ALLOYS
}

\author{
By John A. Scherrer
}

\section{ABSTRACT}

A method is described in which arsenic, antimony, and tin are separated from most of the lead in babbitts, type metals, solders, and the like, by digestion in hydrofluoric, nitric, and sulfuric acids, and from most of the copper, zinc, lead, etc., in brasses and bronzes by digestion in nitric acid, or precipitation by ammonium hydroxide. The three elements are then converted to sulfates, the arsenic and antimony reduced to the trivalent state, and the three then separated by fractional distillation and determined by titration.

When tin and antimony are titrated in solutions of lead-tin-antimony-copper alloys, obtained by dissolving the alloys in sulfuric acid-potassium sulfate, the results for antimony are usually high and for tin usually low.

\section{CONTENTS}

II. Introduction

II. Procedure recommended for the determination of arsenic, antimony, and tin

1. In babbitt metals, type metals, and solders

(a) Preparation of the solution

2. In tin-base alloys

(a) Preparation of the solution

3. In copper-base alloys _........... 98

(a) Preparation of the solution

4. Distillation of arsenic, antimony, and tin _......... 99

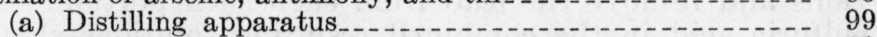

(b) Distillation of arsenic

(c) Distillation of antimony

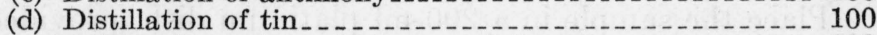

5. Determination of arsenic, antimony, and tin

(a) Arsenic . . .

(b) Antimony

(c) Tin

III. Discussion of results _...

\section{INTRODUCTION}

The determination of antimony and of tin in lead-base and in tinbase alloys is usually made by titration with an oxidizing reagent in a solution of the alloy in sulfuric and hydrochloric acids. In the case of brasses and bronzes whose iron content is low, tin together with antimony and arsenic, if the alloy contains a sufficient proportion of tin, are usually first separated from other constituents by digesting the alloy with nitric acid and filtering the resulting solution. The filter paper and precipitate are decomposed by heating with sulfuric 
and nitric acids, and then the antimony and tin are determined by titration. Arsenic is usually determined by titration after it has been distilled from the solution of a separate sample. Methods of the type just mentioned are subject to a number of limitations. For example, in the determination of antimony by titration with permanganate correction must be made for arsenic. The titration of antimony and tin in the presence of some of the other constituents of these alloys yields values which are usually high for antimony and low for tin. For purposes of rapid control such determinations are satisfactory, except when relatively small amounts of antimony (up to about $20 \mathrm{mg}$ ) are involved. In this instance the result for the determination of antimony may be high by two- or threefold.

If, however, arsenic, antimony and tin are successively removed from solution by distillation as recommended by Scherrer ${ }^{1}$ and subsequently titrated, they can be accurately determined.

With lead-base alloys it is necessary first to eliminate most of the lead either as sulfate or chloride. Clarke, Wooten, and Struthers ${ }^{2}$ have described an extraction apparatus for this purpose which is especially useful when a large amount of alloy must be taken.

In the customary procedures for the removal of lead as sulfate, the precipitate retains more or less of the antimony, tin, and arsenic, but if the lead sulfate is precipitated in the presence of hydrofluoric acid only traces of these elements are retained.

\section{PROCEDURE RECOMMENDED FOR THE DETERMINA- TION OF ARSENIC, ANTIMONY, AND TIN}

\section{IN BABBITT METALS, TYPE METALS, AND SOLDERS}

\section{(a) PREPARATION OF THE SOLUTION}

The quantity of the sample taken should be such that the amount of antimony does not exceed $100 \mathrm{mg}$, the amount of tin not more than $200 \mathrm{mg}$, and the quantity of lead not greater than $5 \mathrm{~g}$. If the amounts of antimony and tin are very small, it is best to take several 5-g portions and remove the lead from each such portion. The volume of sulfuric acid in the combined resulting solutions should not exceed about $10 \mathrm{ml}$.

Place the sample in a $200-\mathrm{ml}$ platinum dish, provided with a platinum or gold cover, add $50 \mathrm{ml}$ of water, $10 \mathrm{ml}$ of nitric acid ${ }^{3}$ and $10 \mathrm{ml}$ of hydrofluoric acid, and heat on the steam bath. When the alloy is completely dissolved, wash and remove the cover, and continue to heat the solution for about 5 minutes, or until oxides of nitrogen are no longer evolved. Remove the dish from the steam bath and add cautiously $16 \mathrm{ml}$ of diluted sulfuric acid $(1+1)$. Stir thoroughly with a platinum stirring rod or wire, or by twirling, and set aside for 30 minutes or more. Filter through a 9-cm filter paper on a hard-rubber funnel and catch the filtrate in a platinum dish. Wash the lead sul-

\footnotetext{
1 J. A. Scherrer, J. Research NBS 16, 253-259 (1936) RP871.

2 Ind. Eng. Chem. Anal. Ed. 29, 349 (1937)

3 Throughout this paper whenever acids are mentioned, nitric acid will mean the concentrated acid of specific gravity 1.42; hydrochloric acid, the concentrated acid of specific gravity 1.18 ; sulfuric acid, the concentrated acid of specific gravity 1.84; phosphoric acid, the acid containing 85 percent of $\mathrm{H}_{3} \mathrm{PO}_{4}$; hydrofluoric acid, the acid containing 48 percent of $\mathrm{HF}$; acetic acid, the glacial acid containing 99.5 percent of acetic acid; hydrobromic acid, the concentrated acid containing 48 percent of HBr; and ammonium hydroxide, the concentrated ammonium hydroxide of specific gravity of 0.90 . Diluted acids will be designated as follows: For example, diluted hydrochloric acid $(1+99)$ will mean 1 part of the concentrated acid of specific gravity 1.18 diluted with 99 parts of water.
} 
fate with 5-ml portions of a solution consisting of $25 \mathrm{ml}$ of distilled water, $5 \mathrm{ml}$ of nitric acid, $5 \mathrm{ml}$ of hydrofluoric acid and $2 \mathrm{ml}$ of sulfuric acid, and contained in a platinum or ceresin vessel. Finally, wash twice with water. Evaporate the filtrate and washings in a platinum dish on the steam bath.

To recover any arsenic, antimony, or tin in the precipitate, remove the paper from the funnel, and sluice the lead sulfate into a $400-\mathrm{ml}$ beaker, using as little water as possible.

Add $20 \mathrm{ml}$ of hydrochloric acid, while agitating vigorously, ${ }^{4}$ to convert the lead sulfate to lead chloride. Add enough of a 40-percent solution of sodium hydroxide (about $20 \mathrm{ml}$ is usually required) to render the solution alkaline and to dissolve the lead chloride completely. Then, while stirring vigorously, add $20 \mathrm{ml}$ of a 25-percent solution of yellow sodium sulfide. ${ }^{5}$ Dilute to about $300 \mathrm{ml}$ with distilled water and digest on the steam bath for at least 1 hour. Filter the solution, and wash the precipitate with a 2-percent solution of the yellow sodium sulfide. Discard the precipitate. Neutralize the filtrate with acetic acid, add $5 \mathrm{ml}$ in excess, and treat with hydrogen sulfide for 5 to 10 minutes. Allow the solution to stand at room temperature for several hours, or overnight. Filter it through a paper, and wash the precipitate with a 1-percent solution of acetic acid saturated with hydrogen sulfide. Reserve the paper and precipitate.

Heat the main solution from which lead sulfate was removed just to fumes of sulfuric acid. Cool somewhat, wash down the sides of the dish, and again heat the sulfuric acid just to fuming to expel any remaining hydrofluoric acid. Transfer the solution to a Kjeldahl, flask with as little water as possible. Heat the solution over a free flame, while agitating it constantly until the water has evaporated. Add the reserved filter paper and precipitate. Let it stand for a few minutes to disintegrate

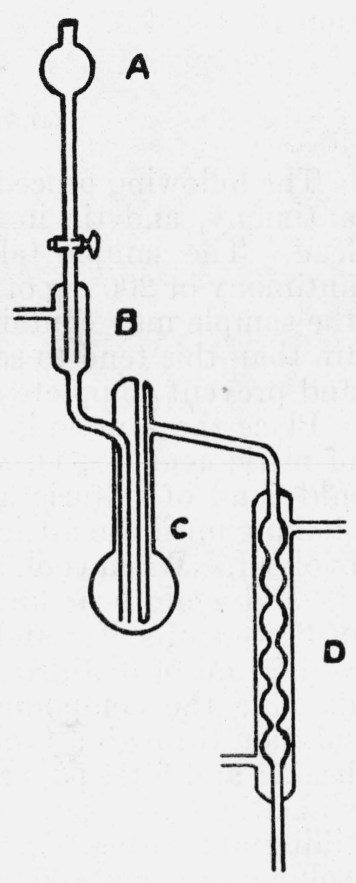

Figure 1.-Distillation apparatus.

the paper, and add about $25 \mathrm{ml}$ of nitric acid. Heat over a direct flame with constant agitation. When most of the nitric acid has been expelled and the solution becomes straw yellow, add cautiously a few milliliters of nitric acid, and continue the heating and agitation until the nitric acid is expelled and fumes of sulfuric acid appear. If the solution darkens, continue the addition of small amounts of nitric acid and the heating until the organic matter is destroyed and the fuming sulfuric acid is colorless, or nearly so. ${ }^{6}$ Cool somewhat, add

\footnotetext{
4 Constant agitation of the lead sulfate during the addition of the hydrochloric acid results in a granular precipitate of lead chloride which does not cake and which dissolves readily in sodium hydroxide. The addition of hydrochloric acid to the lead sulfate facilitates its solution, and the sodium chloride which is formed is desirable as an electrolyte.

${ }_{3}$ The solution of yellow sodium sulfide is prepared as follows: Dissolve $250 \mathrm{~g}$ of colorless sodium sulfide in 1 liter of distilled water. If the solution is not perfectly clear, allow it to stand for several days and siphon off the clear liquid, add about $20 \mathrm{~g}$ of flowers of sulfur and allow to stand with occasional shaking until the solution has a bright yellow color.

${ }_{6}$ If iron, copper, or other elements forming colored ions are present, the sulfuric acid will not be entirely colorless. In such cases the treatment must be continued until no further change of color takes place.
} 
cautiously about $10 \mathrm{ml}$ of distilled water ${ }^{7}$ and evaporate again until fumes of sulfuric acid appear. Add about $0.2 \mathrm{~g}$ of flowers of sulfur to the sulfuric acid solution and boil gently for about 10 minutes to reduce the arsenic and antimony to the trivalent state. ${ }^{8}$ Cool, add about $25 \mathrm{ml}$ of distilled water and $10 \mathrm{ml}$ of hydrochloric acid. Stir to completely dissolve the compounds of arsenic, antimony and tin. Filter the solution through a paper of coarse texture and wash with about $20 \mathrm{ml}$ of diluted hydrochloric acid $(1+1)$. Transfer the solution to the all-glass distilling apparatus (fig. 1), wash the container with $40 \mathrm{ml}$ of hydrochloric acid, and proceed with the distillation and determination of arsenic, antimony and tin, as described in section II, 4 and 5 .

\section{IN TIN-BASE ALLOYS}

\section{(a) PREPARATION OF THE SOLUTION}

The following procedure is designed for the determination of arsenic, antimony, and tin in tin-antimony alloys which contain little or no lead. The sample taken should not contain more than $100 \mathrm{mg}$ of antimony or $200 \mathrm{mg}$ of tin. When only antimony is to be determined, the sample may contain as much as $0.5 \mathrm{~g}$ of tin. Greater amounts of tin than this tend to separate as tin phosphate during the distillation, and prevent complete distillation of antimony.

Place the sample in a $300-\mathrm{ml}$ Kjeldahl flask, cautiously add $20 \mathrm{ml}$ of nitric acid $(1+1)$, and heat until the alloy is decomposed. Cool, add $8 \mathrm{ml}$ of sulfuric acid, and heat over a free flame with constant shaking until the nitric acid is removed and vapors of sulfuric acid are evolved. When cool, add about $10 \mathrm{ml}$ of distilled water (see footnote 7 ), and again heat until the water is expelled. Add a small amount of flowers of sulfur and boil for about 10 minutes. Cool the solution, add $25 \mathrm{ml}$ of distilled water and $10 \mathrm{ml}$ of hydrochloric acid. Stir to dissolve the compounds of arsenic, antimony, and tin. Filter the solution through a rapid filter paper to remove the sulfur. Wash the beaker and filter paper with $30 \mathrm{ml}$ of diluted hydrochloric acid $(1+1)$, added in 4 or 5 portions. Transfer the solution to the all-glass distilling apparatus (fig. 1) with enough hydrochloric acid to bring the volume to about $100 \mathrm{ml}$, and distill and titrate as described in section II, 4 and 5 .

\section{IN COPPER-BASE ALLOYS}

(a) PREPARATION OF THE SOLUTION

For the complete separation of antimony and arsenic along with tin by nitric acid digestion, the tin must be at least 10 times as much as the total amount of antimony and arsenic. If the proportion is less than this pure tin may be added. Since $500 \mathrm{mg}$ of tin is the maximum quantity which is permissible in the distillation of arsenic and antimony the total amount of these elements cannot exceed $50 \mathrm{mg}$. If tin, also, is to be separated by distillation it should not exceed about $200 \mathrm{mg}$.

\footnotetext{
7 The water is added at this point to aid the removal of oxides of nitrogen which are generally present when sulfuric acid solutions containing nitric acid are evaporated.

${ }_{8}$ The entire operation may becarried out in a beaker, if desired.
} 
Place from 1 to $5 \mathrm{~g}$ of the alloy in a $250-\mathrm{ml}$ beaker, provided with a cover, and add 20 to $50 \mathrm{ml}$ of diluted nitric acid $(1+1)$. Boil the solution to expel oxides of nitrogen, dilute to $150 \mathrm{ml}$ with hot water, and allow it to stand on the steam bath for several hours, or overnight. Filter the solution through a paper of close texture and wash the precipitate with hot diluted nitric acid $(1+99) .^{9} \quad$ Place the paper and precipitate in a Kjeldahl flask, and proceed with the destruction of the paper, solution of the precipitate, and reduction with sulfur as in section II, 1 (a). Transfer the solution to the all-glass distilling apparatus (fig. 1) with enough hydrochloric acid to bring the volume to about $100 \mathrm{ml}$, distill and titrate as described in section II, 4 and 5 .

The separation may also be made as follows: Dissolve the sample in aqua regia, and precipitate the arsenic, antimony, tin, etc., by ammonium hydroxide and proceed as described in footnote 9 . The aqua regia must not be heated to more than incipient boiling in order to avoid loss of the elements to be determined.

\section{DISTILLATION OF ARSENIC, ANTIMONY, AND TIN}

\section{(a) DISTILLING APPARATUS}

In figure 1, $A$ is a $50-\mathrm{ml}$ bulb for holding the acid which is added in the course of the distillations. The tube connecting $A$ and $B$, and extending into $B$, is $25 \mathrm{~cm}$ long, in order to overcome the pressure of the carbon dioxide which is used to aid in carrying over the vapors from the distilling flask $C$. The part of this tube extending into $B$ should have a diameter of not over 3 or $4 \mathrm{~mm}$ in order to prevent the acid from draining from it.

$B$ is an arrangement for gaging the rate of flow of the acid, and is provided with a side tube for the purpose of introducing a stream of carbon dioxide.

$C$ is a $200-\mathrm{ml}$ distilling flask, the neck of which is $2.5 \mathrm{~cm}$ in diameter. It is provided with a side tube, a thermometer well, and a delivery tube for conveying the acids and carbon dioxide to the distilling flask. The side tube connects the apparatus to a condenser, the thermometer well is sealed to the top of the neck of the flask, and the delivery tube passes through the wall in the upper part of the neck of the flask and is connected to $B$. Both the thermometer well and the delivery tube reach to within $3 \mathrm{~mm}$ of the bottom of the flask. The distance between the bottom of the flask and the exit tube leading to the condenser is $17 \mathrm{~cm}$.

The apparatus is clamped to a ring stand. $C$ rests on an asbestos board (about 18 by $18 \mathrm{~cm}$ ) having a round hole $4.0 \mathrm{~cm}$ in diameter.

It is desirable that all the glass should be free from the elements in question, and the suitability of the apparatus for the work in hand should be determined by running appropriate blanks.

\section{(b) DISTILLATION OF ARSENIC}

Insert the thermometer in the well, and provide a receiver containing 50 to $100 \mathrm{ml}$ of distilled water into which the end of the condenser

\footnotetext{
If there is an appreciable amount of iron ( $1 \mathrm{mg}$ or more) in the sample the precipitation of tin, etc., will not be complete. To recover it add ammonium hydroxide to the filtrate until it is strongly alkaline, boil, filter, and wash with diluted ammonium hydroxide $(1+10)$. Add the paper and precipitate to the Kjeldahl flask in which the original paper and precipitate were placed. If the quantity of lead exceeds 1 percent, the ammonium hydroxide precipitate should be dissolved in nitric-hydrofluoric acids and lead separated as sulfate as in section II, 1 (a), and any arsenic, antimony, and tin which are recovered added to the Kjeldahl flask with the main precipitate.
} 
dips. Pass a stream of carbon dioxide through the apparatus at the rate of about six to eight bubbles per second, heat the solution to boiling and boil gently until the volume in the distilling flask has been reduced to $50 \mathrm{ml}$. The rate of flow of the carbon dioxide should be regulated so that the temperature will be 110 to $111^{\circ} \mathrm{C}$ at this stage. Without interrupting the stream of carbon dioxide or the heating, remove the receiver and rinse the end of the condenser with distilled water. Reserve the distillate for the determination of arsenic, and place another receiver containing 50 to $100 \mathrm{ml}$ of distilled water in position.

One distillation usually suffices if the amount of arsenic does not exceed $0.001 \mathrm{~g}$. If larger amounts are in question, it is advisable to add $25 \mathrm{ml}$ or more of the acid and repeat the distillation. In analyses of the highest accuracy, especially if the amount of antimony is large, the arsenic should be redistilled, as a few tenths of a milligram of antimony may distill over with the arsenic. In this case transfer the distillate to an empty distilling flask, and again distill until the volume in the flask is reduced to $50 \mathrm{ml}$. Then add $25 \mathrm{ml}$ of hydrochloric acid and continue the distillation until the residue in the flask is again reduced to $50 \mathrm{ml}$. Add the residual solution to the residue left in the first distilling flask.

\section{(c) DISTILLATION OF ANTIMONY}

Add $7 \mathrm{ml}$ of phosphoric acid to the distilling flask, reduce the flow of carbon dioxide somewhat, and increase the rate of heating gradually until the temperature in the flask reaches $155^{\circ} \mathrm{C}$. Then introduce hydrochloric acid from bulb $A$ at a rate of 30 to 40 drops per minute, keeping the temperature in the flask between 155 and $165^{\circ} \mathrm{C}$. One hundred $\mathrm{mg}$ of antimony requires 150 to $175 \mathrm{ml}$ of hydrochloric acid. When all the antimony has been distilled, remove the burner, rinse the end of the condenser, change the receiver for another, and reserve the distillate for the determination of antimony.

\section{(d) DISTILLATION OF TIN}

Allow the solution in $\mathrm{C}$ to cool to $140^{\circ} \mathrm{C}$, return the burner, and add a mixture of three-fourths hydrochloric acid and one-fourth hydrobromic acid to bulb $A$, allowing it to flow into the distilling flask at a rate of 30 to 40 drops per minute, and resume distillation, keeping the temperature at about $140^{\circ} \mathrm{C}$. One hundred $\mathrm{mg}$ of tin requires about $125 \mathrm{ml}$ of the mixed acid. When the distillation is finished, rinse the end of the condenser, and reserve the distillate for the determination of tin.

\section{DETERMINATION OF ARSENIC, ANTIMONY, AND TIN}

Determine the elements in the distillate as follows:

(a) ARSENIC

Neutralize the cold distillate with sodium hydroxide, acidify slightly with hydrochloric acid, and cool to room temperature. Then neutralize it with a saturated solution of sodium bicarbonate and add an excess of $20 \mathrm{ml}$. Titrate the arsenic with a standard solution of $0.01 N$ iodine, using a solution of starch as indicator. Make a 
careful blank run on the same amounts of reagents as were used with the sample, adding $0.1 \mathrm{~g}$ of potassium iodide before titrating, and apply the correction obtained. The iodine solution should be standardized with pure arsenic trioxide.

\section{(b) ANTIMONY}

Neutralize the distillate with ammonium hydroxide and add $3 \mathrm{ml}$ of hydrochloric acid for each $100 \mathrm{ml}$ of solution. Pass hydrogen sulfide through the solution for 15 minutes. Allow the solution to stand for about 30 minutes and filter it. Wash the precipitate with a solution of diluted sulfuric acid $(2+98)$, saturated with hydrogen sulfide. Transfer the paper and precipitate to a Kjeldahl flask, add $10 \mathrm{ml}$ of sulfuric acid, allow it to stand a few minutes, then add about $25 \mathrm{ml}$ of nitric acid, and destroy organic matter and reduce the antimony as described in section II, 1 (a). When the sulfuric acid solution has been boiled with sulfur for about 10 minutes, cool it, add $30 \mathrm{ml}$ of distilled water and boil it until about one-half of the water has been evaporated, to remove sulfur dioxide. Add $25 \mathrm{ml}$ of distilled water and $10 \mathrm{ml}$ of hydrochloric acid, mix thoroughly and pass the solution through a rapid filter paper. Rinse the flask and paper with $60 \mathrm{ml}$ of diluted hydrochloric acid $(1+3)$, added in 4 or 5 portions. (A total of $25 \mathrm{ml}$ of hydrochloric acid should be used.) Dilute the solution in the flask to $300 \mathrm{ml}$, boil it for about 5 minutes, cool to $10^{\circ} \mathrm{C}$, and titrate the antimony with a standard solution of $0.1 \mathrm{~N}$ potassium permanganate. The permanganate solution may be standardized against pure antimony or standard sodium oxalate.

\section{(c) TIN}

Transfer the distillate to an Erlenmeyer flask and add distilled water until the solution contains approximately 30 percent of hydrochloric and hydrobromic acids (by volume). Reduce the tin by boiling it for 30 minutes with an excess of test lead. Cool the solution to $10^{\circ} \mathrm{C}$ and titrate with a standard solution of $0.1 \mathrm{~N}$ iodine, using a solution of starch as indicator. Pass a stream of carbon dioxide through the apparatus ${ }^{10}$ during the reduction, cooling, and titration. The iodine solution should be standardized with weighed portions of pure tin by the procedure used for the sample.

\section{DISCUSSION OF RESULTS}

The data given in table 1 show that accurate results for arsenic, antimony, and tin are obtained by method $A$ when applied to synthetic mixtures representative of lead-base bearing alloys. The amounts of arsenic, antimony, and tin retained by the lead sulfate, even when 5 $\mathrm{g}$ of lead is present, may be disregarded, except in analyses of the highest accuracy. In two experiments, the total recovery of arsenic, antimony, and tin was of the order of $0.2 \mathrm{mg}$ in one case, and 0.1 in the other. When no hydrofluoric acid was used recoveries ranged from 2 to $4 \mathrm{mg}$.

The data in table 2 show that correct results for antimony in synthetic mixtures simulating tin-base alloys are obtained by method $B$.

10 J. A. Scherrer, Determination of tin in irons and steels, BS J. Research 8, 309 (1932) RP415. 
TABLE 1.-Results obtained by applying method A to solutions of synthetic mixtures of the metals

\begin{tabular}{|c|c|c|c|c|c|c|}
\hline \multicolumn{2}{|c|}{ Arsenic } & \multicolumn{2}{|c|}{ Antimony } & \multicolumn{2}{|c|}{ Tin } & \multirow{2}{*}{$\underset{\text { (taken) }}{\text { Lead }}$} \\
\hline Taken & $\begin{array}{l}\text { Recov- } \\
\text { ered a }\end{array}$ & Taken & $\begin{array}{l}\text { Recov- } \\
\text { ered a }\end{array}$ & Taken & $\begin{array}{l}\text { Recov- } \\
\text { ered a }\end{array}$ & \\
\hline & g & & & & & $g$ \\
\hline 0.0010 & 0.0011 & 0. 1064 & 0.1063 & 0.1136 & 0.1136 & 0.8 \\
\hline .0010 & .0009 & .1081 & .1080 & .1094 & .1093 & .8 \\
\hline .0020 & .0019 & $\begin{array}{l}.1001 \\
.1080\end{array}$ & .1081 & .1229 & .1230 & .8 \\
\hline .0100 & .0102 & $\begin{array}{l}.1000 \\
.1202\end{array}$ & .1199 & .1212 & $\begin{array}{l}.1230 \\
.1209\end{array}$ & .8 \\
\hline .0200 & .0199 & .1083 & .1085 & .1283 & .1283 & .8 \\
\hline
\end{tabular}

s These include such amounts of the element as were caught and recovered from the lead sulfate precipitate. In separate experiments it was determined that the total amount of the elements caught rarely exceeded $0.2 \mathrm{mg}$.

TABLE 2.-Results obtained for antimony by applying method $B$ to synthetic mixtures of antimony and tin (no lead present)

\begin{tabular}{|c|c|c|}
\hline \multicolumn{2}{|c|}{ Antimony } & \\
\hline Added & Recovered & \\
\hline & Tin (taken) \\
\hline $\mathbf{g}$ & $\mathrm{g}$ & $\mathrm{g}$ \\
0.0599 & 0.0600 & 0.5 \\
.1025 & .1025 & .5 \\
.0512 & .0513 & .5 \\
.1032 & .1010 & $\mathrm{a} 2.0$ \\
.0278 & .0271 & $\mathrm{a} 2.5$ \\
.0523 & .0518 & $\mathrm{a} 2.5$ \\
\hline
\end{tabular}

a These 3 determinations show that tin should not exceed $0.5 \mathrm{~g}$.

The reduction of arsenic and antimony by sulfur is rapid, and the excess of sulfur can be removed by filtration. Other reducing agents such as ferrous sulfate, cuprous chloride, potassium bromide, phosphorous acid, or organic substances (such as filter paper, ${ }^{11}$ tartaric acid, and hydrazine sulfate), have been used in special cases. Under certain conditions, some of these, for example, phosphorous acid and hydrazine sulfate, reduce arsenic compounds to the metallic state. Bromides, which are sometimes added along with hydrazine sulfate and other reducing agents, must not be present when antimony and tin are to be separated, since even small amounts of hydrobromic acid cause tin to distill partially with the antimony. Ferrous sulfate and cuprous chloride can be used to reduce arsenic if it is determined in a separate sample.

If tin and antimony are titrated in solutions of alloys which contain lead, tin, antimony, and copper, obtained by dissolving the alloys in sulfuric acid and potassium sulfate, the results for antimony are usually high and for tin usually low. This is demonstrated by the data given in tables 3 and 4 . Similar effects have been observed in experiments on the titration of antimony in synthetic mixtures of

\footnotetext{
${ }^{11}$ In the author's experience, reduction by means of filter paper is not satisfactory.
} 
high-purity lead, tin, and antimony. For example, when the direct titration for antimony (footnote $b$, table 3 ) was applied to a mixture of $20 \mathrm{mg}$ of antimony and $1 \mathrm{~g}$ of lead, the results obtained for antimony were consistently 1 to $2 \mathrm{mg}$ too high. The same positive error was obtained, in the presence of lead, when the solution was first oxidized with permanganate, prior to reduction with sulfur. On the other hand, when the direct titration procedure for antimony (footnote $b$, table 3) was applied to a mixture of $100 \mathrm{mg}$ each of antimony and high-purity copper, the results (blank for copper deducted) were about $1 \mathrm{mg}$ low.

TABLE 3.-Comparison of the results obtained in the analysis of white metals by method $A$ and by direct titration

\begin{tabular}{|c|c|c|c|c|c|}
\hline \multirow[b]{2}{*}{ Material } & \multicolumn{2}{|c|}{ Antimony } & \multicolumn{2}{|l|}{ Tin } & \multirow[b]{2}{*}{ Remarks } \\
\hline & $\begin{array}{l}\text { Method } A \\
\text { distillation } \\
\text { procedure }\end{array}$ & $\begin{array}{l}\text { Direct } \\
\text { titra- } \\
\text { tion b }\end{array}$ & $\begin{array}{l}\text { Method } A \\
\text { distillation } \\
\text { procedure }\end{array}$ & $\begin{array}{l}\text { Direct } \\
\text { titra- } \\
\text { tion } 0\end{array}$ & \\
\hline $\mathrm{Pb}-\mathrm{Sn}$ solder $A$..... & $\begin{array}{l}\% \\
0.064\end{array}$ & $\begin{array}{l}\% \\
0.17\end{array}$ & $\%$ & $\%$ & 2.5.g sample for method $A . \quad 0.05 \%$ \\
\hline $\mathrm{Pb}-\mathrm{Sn}$ solder $B$ & .13 & .22 & & & 1-g sample for method $A .0 .06 \%$ As \\
\hline Pb-Sn solder $C$..... & .29 & .41 & & $-\cdots$ & $2.5-\mathrm{g}$ sample for method $A .0 .04 \%$ As \\
\hline $\mathrm{Pb}-\mathrm{Sb}$ alloy......... & .81 & .88 & & $-\cdots$ & 5-g sample for method $A .0 .05 \%$ As \\
\hline $\begin{array}{l}\text { Lead-base bearing } \\
\text { metal. }\end{array}$ & 10.28 & 10.34 & 10.22 & 10.12 & $\begin{array}{l}\mathrm{Pb}=79.35 ; \mathrm{As}=0.07 ; \text { small amounts of } \mathrm{Bi} \text {, } \\
\mathrm{Ag}, \mathrm{Fe}, \mathrm{Ni} \text {, and } \mathrm{Cu} \text {. }\end{array}$ \\
\hline
\end{tabular}

a The completeness of the distillations of antimony and tin was checked, by changing receivers, adding more hydrochloric and hydrochloric-hydrobromic acids, respectively, and testing the distillates obtained. No antimony or tin was detected.

b Sample decomposed in sulfuric acid and potassium sulfate, and $275 \mathrm{ml}$ of water and $25 \mathrm{ml}$ of hydrochloric acid added. Solution boiled, cooled, and titrated with potassium permanganate. Apparent percentage of antimony corrected for arsenic by multiplying the percentage of arsenic (obtained on a separate sample) by 1.86 and deducting.

o Solution from the antimony titration, footnote b, treated with $80 \mathrm{ml}$ of hydrochloric acid, reduced with test lead, cooled, and titrated in the presence of carbon dioxide with iodine.

TABLE 4.-Comparison of the results obtained in the analysis of Ounce Metal by method $C$ and by titration without separation of antimony and tin by distillation

\begin{tabular}{|c|c|c|c|c|}
\hline \multicolumn{2}{|c|}{ Antimony } & \multicolumn{2}{|c|}{ Tin } & \multirow[b]{2}{*}{ Remarks } \\
\hline $\begin{array}{l}\text { Method } C \text { distilla- } \\
\text { tion procedure }\end{array}$ & $\begin{array}{l}\text { Titration } \\
\text { without } \\
\text { distilla- } \\
\text { tion a }\end{array}$ & $\begin{array}{l}\text { Method } C \\
\text { distillation } \\
\text { procedure }\end{array}$ & $\begin{array}{l}\text { Titration } \\
\text { without } \\
\text { distilla- } \\
\text { tion b }\end{array}$ & \\
\hline $\begin{array}{r}\% .222 \\
.224 \\
.227 \\
.228\end{array}$ & $\begin{array}{c}\% \\
0.24 \\
.26 \\
.22 \\
.23\end{array}$ & $\begin{array}{l}\% \\
4.68 \\
4.67 \\
4.69 \\
4.70\end{array}$ & $\begin{array}{l}\% \\
4.55 \\
4.63 \\
4.58 \\
4.60\end{array}$ & \multirow[t]{2}{*}{$\begin{array}{l}\text { This sample also contains approx. } \\
84 \% \text { of } \mathrm{Cu}, 5.5 \% \text { of } \mathrm{Zn} ; 4.8 \% \text { of } \\
\mathrm{Pb} 0.45 \% \text { of } \mathrm{Ni} ; 0.37 \% \text { of iron } \\
\text { and small amount of Si, } \mathrm{S} \text {, and } \\
\mathrm{P} \text {. (As not detected.) }\end{array}$} \\
\hline Average.. 0.225 & 0.24 & 4. 69 & 4. 59 & \\
\hline
\end{tabular}

a Alloy treated with diluted nitric acid and the residue of antimony, tin, arsenic, etc., filtered off and reserved. The filtrate was treated with ammonium hydroxide and the precipitate together with the first residue then treated with sulfuric-nitric acids, the solution diluted and titrated with permanganate after adding hydrochloric acid, boiling, and cooling.

b Solution from the antimony titration, footnote a, reduced with test lead and titrated with iodine. 
Tests on the determination of tin in a synthetic mixture of $100 \mathrm{mg}$ of copper, and $800 \mathrm{mg}$ of lead, made by dissolving the metals in sulfuric acid, reducing with test lead, and titrating with iodine (footnote c, table 3) yielded results for tin that were about $1 \mathrm{mg}$ low. With mixtures of only tin and antimony, both of high purity, correct results were obtained for both by direct titration (footnotes b and c, table 3 ).

Determinations of arsenic in lead-base and tin-base alloys, made by decomposing the samples in sulfuric acid and then separating the arsenic by distillation, yielded accurate results, showing that no arsenic is lost during the initial solution in the concentrated acid.

Washington, February 10, 1938. 